\title{
La Milicia Nacional como articulación y vertebración del liberalismo en el Valle Medio del Ebro. Aragón, Navarra y La Rioja (1820-1823)
}

The National Militia as Articulation and Structuring of the Liberalism in the Middle Valley of the Ebro. Aragón, Navarra and La Rioja (1820-1823)

\author{
Sergio Cañas Díez \\ Instituto de Estudios Riojanos \\ https://orcid.org/0000-0003-2789-3315
}

Francisco Javier Díez Morrás

Universidad de La Rioja

DOI: https://doi.org/10.25032/crh.v6i11.6

Recibido: $24 / 11 / 2020$

Aceptado: $30 / 9 / 2020$

Resumen: La Milicia Nacional fue una importante herramienta sociopolítica del primer liberalismo español de especial trascendencia durante el Trienio Liberal. Pese a ser un cuerpo originalmente local según lo previsto por la Constitución de 1812, el análisis comparado de las milicias aragonesas, navarras y riojanas permite verlas como un elemento cohesionador del Estado liberal en el Valle Medio del Ebro. Porque al tiempo en que coadyuvaron a la defensa militar de la Revolución de 1820 y a la derrota de las fuerzas realistas, sirvieron en un plano político para articular y vertebrar la estructura interna del Estado liberal en España. Reforzando los lazos ideológicos entre los patriotas de distintas localidades y provincias y materializando, en suma, la idea de la ciudadanía en armas en defensa de la nación.

Palabras clave: Milicia Nacional; Constitución de Cádiz; Revolución de 1820; Valle del Ebro.

Abstract: The National Militia was and important socio-political tool of the first Spanish liberalism of special transcendence during the Liberal Triennium. Despite being an originally local body acording to the provisions of the Constitution of 1812, the comparative analysis of the Aragonese, Navarrese and Rioja militias allows to see them as a cohesive element of the liberal State in the Middle Valley of the Ebro. Because 
at the time they contributed to the military defense of the Revolution of 1820 and the defeat of the royalist forces, served on a political level to articulate and back up the internal structure of the liberal state in Spain. Reinforcing the ideological ties between the patriots of different localities and provinces and materializing, in short, the idea of citizenship in arms in defense of the nation.

Key words: National Militia; Constitution of Cádiz; Revolution of 1820; Ebro Valley.

\section{Introducción}

El Estado es un producto de una sociedad compleja situado a la vez entre las clases sociales, los individuos que las componen, y por encima de ellos, para mantener el orden político y proteger la propiedad (Engels, 2017, 227 y 230). En su desarrollo histórico, el Estado liberal es la conquista del poder político de la burguesía para detentar el poder político (Marx y Engels, 2011, 33). Para crearse, perdurar y reproducirse el Estado necesita de la fuerza y arrogarse «el monopolio de la violencia física legítima» en el territorio que controla, produciendo «una relación de dominación» sostenida «por medio de la violencia legítima» (Weber, 1979, 83 y 84). Pero también precisa producir cambios culturales y mentales que legitimen el poder del Estado por parte de los ciudadanos para que se involucren en su maquinaría política o militar (Pro, 2016, 2).

Dentro de esa fuerza estatal y sobre la base de la legitimación cultural sobresale en el primer liberalismo español (1808-1840) el Ejército y la Milicia Nacional, entendida como un cuerpo armado de ciudadanos. ${ }^{1}$ Que por un lado inventa el liberalismo en la concreción histórica que da al Estado, y por el otro lado es la evolución lógica de sus inmediatos antecedentes históricos. Como la Milicia Urbana, creada para proteger las ciudades mientras el Ejército luchaba contra la República francesa (17931795). La cual respondía a la ideología absolutista del reinado de Carlos IV para reforzar el orden antiguorregimental en contra del régimen liberal y revolucionario de Francia (Pérez Garzón, 1978, 9-12). Esta milicia denota la voluntad de mantener el orden

${ }^{1}$ En el primer liberalismo español hay tres fuerzas armadas oficiales: el Ejército, la Milicia Nacional Activa y la Milicia Nacional Local, que se divide a su vez en Voluntaria o Legal (también conocida como Forzosa) según se reclute de manera volitiva o por recluta obligatoria (Seco, 49). Este trabajo solo analiza la Milicia Nacional Local. 
antiguo y la sociedad estamental, dándole preeminencia a la nobleza frente a la burguesía comercial y excluyendo a artesanos y campesinos (Espadas, 1972, 10).

Desde esos parámetros intervendrá al servicio de Fernando VII en la Guerra de la Independencia, teniendo su contrapunto político en la Milicia Cívica de José I, destinada a combatir el bandidaje y la guerrilla española en pos del régimen afrancesado, y también en la Milicia Nacional, nacida al calor de la Constitución de 1812 y de la revolución liberal española (Pérez Garzón, 1978, 30-36). El cambio frente a la milicia liberal es evidente porque representan dos modelos estatales antagónicos. Pese a que cabe hablar de evolución porque se mantienen algunas características, su significado histórico es diferente porque la Milicia Nacional tiene el germen revolucionario en su seno: su fin es la defensa de la soberanía nacional y se nutre del ciudadano, «el ciudadano soldado», representante de «la nación en armas». No lucha, como su antecesora, por el rey como monarca absoluto (Chust y Marchena, 2007, 9). Pues estaba al servicio de los postulados liberales, como los líderes políticos reconocieron en el siglo XIX (Romero, 1989, 214).

Este cambio también influyó en la articulación del propio Estado, donde todavía se debate la dicotomía entre centralismo -en ocasiones confundido con uniformidad- y localismo - equiparado de modo simplista con alteridad- para caracterizar los modelos absolutista y liberal. Por un lado porque la centralidad absolutista era más limitada y matizada que lo que se pensaba por la importancia que tuvieron los poderes locales. Y precisamente ese protagonismo ha contribuido a cuestionar la continuidad centralizadora del Estado español en el paso del viejo al nuevo régimen (Millán, 2011). Pero también porque el papel de los ayuntamientos en el proceso de construcción del Estado del siglo XIX fue más protagónico que lo se ha dicho, habiendo espacio para la cooperación, la resistencia, la negociación y el enfrentamiento frente a la administración superior (Veiga, 2017). Así, mientras que las milicias absolutistas se sometían al poder de la Corona, representando «el mayor nivel posible de centralización» (Rico, 1983, 74), la estructura de la Milicia Urbana de 1808 encarna la creciente importancia del poder local que será decisiva para el régimen liberal (Pérez Garzón, 1978, 71). Una tendencia que refuerza la propia Constitución de 1812 cuando crea la Milicia Nacional regida por los ayuntamientos, pues a consecuencia de la descentralización del poder se va construyendo el Estado nacional en España mientras finaliza el modelo imperial del Estado absoluto (Pro, 2016, 5). En 
ese sentido «la Milicia era local» porque queda bajo control municipal. Por eso su denominación completa es Milicia Nacional Local aunque su relieve fuera nacional porque forma parte del nuevo régimen que se constituye como Estado nacional (Pérez Garzón, 1978, 163), lo que vincularía la Milicia Nacional con el proyecto de «descentralización» de las provincias y del «centralismo democrático desconcentrado» de los ayuntamientos, como lógicas que articulan el primer Estado liberal en España (Gallego, 1991, 154). Al menos esa fue la apuesta del progresismo liberal, cierta descentralización del poder político en favor del poder local, que era finalmente quien administraba los pueblos y las ciudades españolas (De Castro, 1979, 83).

Por otro lado la Milicia Nacional es al mismo tiempo derecho y obligación constitucional. Es un deber ciudadano que lo une al Estado quien le exige defender la nación y su territorio (Moliner, 2012, 142). Lo que empareja la suerte de la Constitución, de la milicia y de la propia ciudadanía: liga a los ciudadanos con el régimen liberal y contra el Antiguo Régimen encargándoles de la protección armada del nuevo Estado (Chust y Serrano, 2007, 82). Es un medio de compulsión constitucional (Artola, 1991, 120) y el brazo armado de la revolución liberal burguesa (Garralda, 1988, 319) nutrida de ciudadanos liberales organizados militarmente para defender el nuevo régimen (Naranjo, 2016, 640). En ese sentido forma parte de la lucha de clases porque además de defender la superestructura del orden constitucional, se institucionaliza la organización armada de la clase propietaria que surge de las nuevas relaciones de producción (Pérez Garzón, 1978, 104). También la Milicia Nacional es un factor de nacionalización porque genera «un espíritu de cuerpo y una identidad política» que incluye a los milicianos en «una comunidad imaginada nacional», aunque les sirva para presionar a las autoridades en clave liberal radical. Pues la milicia les sirve para ser «ciudadanos activos por la causa liberal» y para tener protagonismo político al margen de las autoridades políticas (Veiga, 2016, 12).

Las lecturas sobre el fin de la Milicia Nacional tuvieron un correlato ideológico que debe precisarse para entender mejor la relación entre los milicianos y los ayuntamientos del Trienio. Para la narrativa liberal progresista era la representación de la ciudadanía en armas en un sentido radical, era «el pueblo armado por sus derechos en defensa de su soberanía» que lucha por defender la patria. Es el «más firme apoyo del orden público» y la mejor «garantía de nuestras libertades» (Ruíz de 
Morales, 1855, 2). Desde ese punto de vista la Milicia Nacional es una organización propia de una democracia militar (Gallego, 1991, 157). Mientras que para los moderados solo debía velar por la seguridad pública como si fuera un cuerpo policial (Guerrero, Pérez y Rueda, 2004, 96). Esta disyuntiva origina que, aunque inicialmente fuera un cuerpo nacido en defensa del régimen liberal, cuyo objetivo era «velar por el orden público y el orden político», poco a poco fuese dominada por el liberalismo exaltado y radical que hizo de la milicia la cristalización de la patria armada (Sánchez Mantero, 1996, 87-88). De esta interpretación provienen distintas iniciativas milicianas para combatir a las tropas realistas fuera de sus fronteras locales $\mathrm{y}$ comarcales, si bien, la propia legislación permitía esas operaciones en casos extraordinarios y urgentes. El problema estaba en saber en qué momento activar esa posibilidad y en la propia sensibilidad política e inteligencia militar de los ayuntamientos que, como veremos, no era la misma que la del común de los milicianos.

Los autores del siglo XIX tuvieron claro que la Milicia Nacional fue un agente activo de la revolución dentro y fuera de los territorios donde se formaron:

La dignísima y valiente Milicia Nacional de aquella época merecía en todas partes bien de la patria: sus servicios no se reducían solamente a mantener las leyes y el orden público en las poblaciones y a exterminar las partidas facciosas donde quiera se presentaban, sino también a perseguir los criminales y los ladrones (Ruiz de Morales, 1855, 171).

Es un hecho confirmado por lecturas liberales más conservadoras, que interpretaron que la milicia del Trienio «más necesitaba de freno que de espuela, y no había para qué concitarla; el trabajo estaba en reprimirla» (Lafuente, 1888, 272). En determinadas circunstancias podían reforzar al Ejército fuera de su demarcación, es decir, ser empleadas como tropas auxiliares cuando la autoridad lo ordenase (Blanco, 1988, 201).

Otra de las ideas dominantes en la historiografía es que su indisciplina e insubordinación les hacían ser ineficaces e incompatibles con el Ejército, por lo que progresivamente fueron transformándose en una fuerza local dependiente del ayuntamiento que, simultáneamente, fue mediatizado por la propia milicia. Se observa en poblaciones menores donde la Milicia Nacional se distingue por defender el liberalismo y trastocar el orden político ante desórdenes políticos locales (Sánchez Mantero, 1996, 89-90). Si bien otras interpretaciones consideran que así como los realistas se opusieron a la Milicia Nacional frontalmente por ser garante del nuevo 
orden, también el liberalismo moderado trató de reformarla y limar su influencia política cuando la milicia representaba «la vertiente armada del liberalismo radical y popular», sobre todo en las ciudades por ser donde tuvieron mayor protagonismo político (Chust y Serrano, 2007, 86). Pues para los moderados también fue una herramienta para «incidir y acercarse al mundo popular» (Roca, 2007, 16).

Así, a la motivación defensiva y de seguridad, donde trabajos más recientes han resaltado su papel policiaco a medio camino entre el orden público y el orden político (París, 2020, 218 y 220), se le une un plano político y social que institucionaliza la Milicia Nacional con base a la Constitución de 1812 pero adaptada y desarrollada a las necesidades de los gobiernos del Trienio. Y de la burguesía como nueva clase dominante. Porque fueron las sociedades patrióticas las que presionan para restablecer la Milicia Nacional desde el principio frente a los ayuntamientos, más moderados, que se resisten en la medida de lo posible tanto por razones económicas como porque no quieren perder o compartir el poder político a pesar de que la ley les asegura mandar y formar la milicia (Pérez Garzón, 1978, 83). Pues las sociedades y las milicias son formas de organización política que permiten la creciente movilización popular en el primer liberalismo español y garantizan su consolidación (Roca, 2007, 29).

En cuanto al ámbito donde la Milicia Nacional tuvo mayor importancia, la historiografía local y regional ha demostrado que también fue importante al margen de los grandes centros urbanos. Así como las limitaciones y déficits que tuvo para formarse en algunas regiones enteras, como Extremadura, en algunas provincias, como Lérida y Tarragona, o en algunas ciudades concretas, como Zamora (García, 1983; Chust, 1987; Casals, 2000; Veiga, 2016; Codesal, 2008; Naranjo, 2016; Arnabat, 2001; Cañas, 2016; Díez, 2019). ${ }^{2}$ De ahí que se haya señalado la dificultad de crear un cuerpo miliciano en cada municipio frente a la facilidad con que se logró en las capitales provinciales, cabezas de partido y localidades más pobladas de cada región (Calles, 2015, 236).

\footnotetext{
${ }^{2}$ Lógicamente el número de trabajos locales y regionales sobre la Milicia Nacional es mayor a la nómina que presentamos. Por razones de espacio solo referimos aquí a las primeras aportaciones bibliográficas sobre algún territorio o a las últimas tesis doctorales que informen sobre el particular. Pues otros trabajos son usados en otra parte del artículo y se pueden ver la relación total en el apartado bibliográfico.
} 
La zona del Valle Medio de Ebro resulta especialmente interesante para analizar la Milicia Nacional desde un punto de vista militar y político porque es un área con unas características geográficas y económicas comunes. Así, el objetivo del presente trabajo es observar a través de los ejemplos de La Rioja, Navarra y Aragón, las tres regiones que la componen, el diverso arraigo que consiguió el liberalismo y la importancia fundamental de la Milicia en el intento por afianzar el primer constitucionalismo español. Para su estudio se ha acudido a las fuentes archivísticas locales, por la total imbricación de las milicias en su entorno local, y hemerográficas.

\section{La Milicia Nacional en el marco de la Constitución de 1812}

La relación entre la Milicia Nacional y la revolución burguesa de cara a definir el Estado moderno en España, es decir, la nación política española, se origina y plasma claramente en la propia Constitución de 1812. Por eso la construcción de la milicia va pareja a la construcción de la España liberal, aunque la Constitución de Cádiz no fue tanto una meta como un punto de salida (Casado, 1982 104). La Constitución disponía cuatro bases para la creación de esa fuerza sintetizados en: su naturaleza cívica, su carácter extraordinario, su pleitesía frente al Estado y, excepcionalmente, su servicio a la Corona cuando lo dictasen las Cortes. 3 Lo cual era un principio pero dejaba «cabos sueltos» para asegurar y afianzar el régimen liberal (Sánchez Jiménez, 1991, 56).4 Por eso para regular la milicia de modo más específico se derivaba a una legislación particular posterior que fue modificada varias veces.

El primer reglamento de la milicia llega en 1814, estableciendo la obligación de servir a todo ciudadano español y varón con una edad comprendida entre 30-50 años. Exceptuando a los ciudadanos que tuvieran los derechos suspensos, miembros del clero (ordenados in sacris, tonsurados y menores aforados), miembros del Gobierno nacional, de la Magistratura, de la Hacienda y funcionarios a su servicio, jefes políticos y alcaldes, personal higiénico-sanitario (médicos y cirujanos titulares, y veterinarios cuando sean los únicos de la población), y al personal docente (maestros y catedráticos). La duración del servicio era de 8 años. Y cada población tendría una fuerza relativa al tamaño de su población, desde la escuadra de 20 milicianos de

3 Constitución Política de la Monarquía española, 18 de marzo de 1812. Título viII, capítulo II, art. 362365 .

4 De inicio no estaba clara la capacidad de la Corona para disponer de la Milicia Nacional aunque no fuera asimilable al mando que tenía sobre el Ejército y la Armada (Escudero, 220). 
infantería de los sitios más pequeños hasta los dos batallones con diez compañías de infantería (1200 unidades) de los grandes municipios. Sus obligaciones eran proteger el ayuntamiento y los espacios públicos, mantener la tranquilidad y la seguridad local, patrullar las calles, acudir a las funciones públicas, perseguir delincuentes, escoltar «en defecto de otra tropa» presos y caudales públicos desde su pueblo al inmediato donde haya milicia que pueda continuar el servicio, 5 y defender la propiedad privada $\mathrm{y}$ municipal «de los enemigos exteriores o interiores». El alistamiento era voluntario, cubriéndose mediante un sorteo vecinal las plazas desiertas si no se completara la milicia por la primera vía. La oficialidad de la Milicia Nacional se elegía por votación de los propios milicianos «ante los respectivos ayuntamientos», y la plana mayor era elegida del mismo modo por la oficialidad. Si bien en caso de que concurrieran oficiales retirados del Ejército o la Armada tenían prioridad para ejercer su grado, y donde hubiera un gobernador o comandante militar «con nombramiento real» serían los jefes natos de la milicia. El servicio era gratuito, no debiendo percibir ni abonar nada por prestarlo, si bien cuando salieran de partida o se empleasen en un servicio extraordinario percibían de cinco a ocho reales en función del grado y empleo. Estando los ayuntamientos obligados a su abono. ${ }^{6}$

El diseño original de la milicia pensó en la infantería, pero en las localidades más pobladas se podían formar milicias de caballería siguiendo la misma proporción que en el arma de infantería. La unidad mínima era la escuadra de caballería de diez hombres y la máxima el escuadrón (62 a 72 milicianos) de tres a cinco compañías (200360 efectivos). Si un pueblo prefería solo dotarse de caballería por sus circunstancias o de ambas armas, por tener suficiente población para ello, lo podía plantear al gobierno.7

Esta Milicia Nacional juraba ante Dios servir con las armas a la patria, defender la religión católica, conservar el orden interior local, guardar y hacer guardar «si alguna vez os compitiere» la Constitución de 1812, ser fieles al rey y «custodiar y defender su persona sagrada e inviolable», sujetarse a la ley militar, obedecer a sus oficiales, seguir

\footnotetext{
5 En caso de que el pueblo del itinerario no tuviera fuerza suficiente, prestaría el servicio otro pueblo de la comarca que pudiera darlo.

${ }^{6}$ Decreto LXXIII, 15 de abril de 1814. Reglamento para la Milicia Nacional. Capítulo I, art. 1-17; Capítulo II, art. 19-25; Capítulo III, art. 26- y 39; Capítulo IV, art. 44; Capítulo VI, art. 48-50 y 53.

7 Ibídem. Capítulo XI, art. 59.
} 
las banderas nacionales «defendiéndolas hasta morir», no abandonar su puesto de servicio ni al jefe que los mandara en acto de servicio, y guardar la debida consideración al resto de españoles. Lo que es fiel reflejo del espíritu liberal del sistema constitucional español creado en las Cortes de Cádiz. A pesar de que se trataba de una milicia ciudadana, siempre y cuando estuvieran de servicio activo tendrían el estatus de cuerpo militar, el cual perdían cuando regresaban a su vida cotidiana aunque siguieran siendo milicianos, razón por la que serían juzgados por las autoridades y leyes civiles cuando eran civiles, pero por las autoridades y ordenanzas militares cuando estuvieran en servicio. ${ }^{8}$

Pero 1812 no era 1814 ni 1820 (Rújula y Chust, 2020, 9), y el trienio fue un período fructífero desde la óptica del derecho militar (Gil, 1999, 45). Es la época donde se crea la legislación básica y se perfilan los instrumentos políticos mediante los cuales la burguesía tomará el poder (Gil Novales, 2020, 69). Tras el triunfo de la Revolución de 1820 se hizo necesario restablecer la milicia nacional y modificar el Ejército, todo con arreglo a la Constitución de 1812 pero con leyes nuevas. Y convencido el gobierno provisional «del grande influjo que debe tener» la Milicia Nacional «en el buen orden interior de los pueblos y tranquilidad de sus habitantes», se aprobó un reglamento provisional para crear la Milicia Nacional Local con cambios sustanciales frente a la norma de 1814.9 Para empezar porque añadía la característica municipal a la denominación y se establecía que solo se levantaría un cuerpo «en las capitales de provincia y de partido, y en los demás pueblos cuyos ayuntamientos lo pidan». No siendo obligatorio, el servicio lo podían prestar todos los varones españoles de entre 18 y 50 años en el ejercicio de los derechos de ciudadanía, «siempre que se obligue a uniformarse a su costa» y cumplieran el reglamento, lo que por un lado abría la base demográfica para ser miliciano pero por otro lo cerrada, desde el punto de vista socioeconómico, reforzando el carácter burgués de la tropa y de la revolución. Además simplificaba mucho el tipo de tropa que podía crearse en función del tamaño de la población, formando una escuadra donde hubiera entre veinte y treinta milicianos, en pequeños municipios, o un regimiento de dos batallones con diez compañías (unos 1200 hombres) en las grandes localidades. Sus obligaciones eran las mismas que en 1814, no así el uniforme, que antes debía ser azul turquí con botones blancos y botas

\footnotetext{
8 Ibídem. Capítulo vII, art. 54.

9 Real orden de 24 de abril de 1820.
} 
negras, y ahora cada milicia tendría un uniforme determinado por la autoridad política y militar de la provincia, «cuidando sobre todo que sea airoso, cómodo, barato y de género del país».10 Todo esto rompía con la uniformidad establecida en el reglamento anterior.

Casi sin dar tiempo para ejecutar totalmente la norma anterior, el 31 de agosto se fechaba una nueva regla provisional. Sustancialmente no era diferente de la anterior pero corregía algunos aspectos importantes, pues decretaba la obligación de servir bajo las mismas premisas de antes, exceptuando a delincuentes y ciudadanos con algún grado de invalidez que les impidiera manejar armas. Por lo demás, este texto presentaba las mismas excepciones que el reglamento de 1814 en cuanto al clero, profesionales liberales, funcionarios, jueces y gobernantes. ${ }^{11}$ Pero también introducía un matiz de clase al apartar del servicio a «los simples jornaleros y los marineros», estableciendo un criterio plutocrático novedoso a pesar de que su espíritu no fuera sustancialmente diferente a la obligación del reglamento de abril de1820 en lo relativo a costearse el uniforme. Otra de las novedades fue la reducción del número de milicianos necesario para crear un cuerpo de tropa en cada municipio, pudiendo ser la milicia más pequeña de 10 hombres. Y el aumento ilimitado del número máximo de tropa para las grandes ciudades, siendo la mayor de tres batallones con 12-15 compañías (1200 a 1500 efectivos), pero pudiendo ampliarse proporcionalmente según el tamaño de la población. Los milicianos que ya se hubieran alistado, normalmente vinculados con la revolución liberal y con una ideología exaltada en comparación con la moderación de los gobernantes y autoridades políticas, recibirían «el título de voluntarios» y seguirían en servicio, aunque «en lo sucesivo no se admitirán de esta clase». A partir de ese momento eran todos los reclutados milicianos de la ley o forzosos, con una ideología y compromiso constitucional más abierto en conjunto. ${ }^{12}$

Las obligaciones de la milicia no variaron demasiado frente a las normas anteriores, aunque se permitía que la persecución de malhechores «en el pueblo y su

\footnotetext{
10 Reglamento provisional para la milicia nacional local en la península e islas adyacentes. Insertado en Real Orden de 24 de abril de 1820. Capítulo I, art. 1-12; Capítulo II, art. 15-19; Capítulo vII, art. 25.

${ }_{11} \mathrm{Si}$ bien no estaban obligados al servicio, podían alistarse voluntariamente siempre y cuando cumpliesen el resto de obligaciones del reglamento.

12 Decreto XVI de 31 de agosto de 1820 . Reglamento provisional para la Milicia nacional local. Capítulo I, art. 1-14.
} 
término» pudiera desempeñarla un «sustituto que merezca la aprobación del jefe» siempre que fuera miliciano y lo pagase «el individuo a quien corresponda el servicio».13 Un aspecto nuevo, importante para las tesis que defendemos en este artículo, era el artículo vigesimosegundo, que establecía que las autoridades políticas que necesitasen el servicio de la milicia del pueblo más cercano las tenían que pedir por escrito a otro ayuntamiento, no pudiendo ser negado el auxilio si estaba justificada la petición de socorro. El pueblo aludido se hacía responsable de los males que pudieran sobrevenir en caso de no prestar ayuda. ${ }^{14}$ Como novedad se observa la total sujeción de la milicia a la orden de la autoridad superior política local «que en todo caso grave obrará de acuerdo con el ayuntamiento», así como la dotación de mayor solemnidad a los juramentos de los milicianos en un oficio religioso al que acudiría toda la tropa en formación, ${ }^{15}$ donde el cura les recordaría sus obligaciones patrióticas y especialmente la obligación de defender la independencia y libertad de la patria materializadas en la Constitución. La autoridad política local tomaría juramento al comandante de la milicia y, después, este les preguntaría a los milicianos si juraban ante Dios defender con las armas la Constitución, obedecer las órdenes y no abandonar en acto de servicio. También aclaraba las penas en que incurrirían los milicianos por desobediencia e injurias a sus jefes, descuido o abandono del servicio, y la naturaleza cívica de la milicia. Los oficiales debían saber que eran ciudadanos mandando ciudadanos, y los milicianos que cuando terminaban el acto de servicio volvían a ser ciudadanos comunes. En cuanto al uniforme, este reglamento no obligaba a usarlo, pero sí disponía el uso obligatorio de la escarapela. Si los milicianos quisieran uniformarse deberían usar el uniforme azul prescrito en 1814 para infantería, y el uniforme verde oscuro para la caballería. Para los batallones se dispuso el uso de una bandera roja y amarilla (la rojigualda o bicolor característica de España en la actualidad) donde se inscribiría el nombre de la provincia, en las partes rojas, y Constitución, en la amarilla. ${ }^{16}$

\footnotetext{
13 Igualmente todo estudiante, artesano, labrador o propietario podía pedir licencia para no interrumpir su actividad privada.

14 Decreto XVI de 31 de agosto de 1820. Reglamento provisional para la Milicia Nacional Local. Capítulo II, art. 15-26.

15 Donde hubiera más de un batallón, solo acudiría el que debiera jurar.

16 Decreto Xvi de 31 de agosto de 1820. Reglamento provisional para la Milicia Nacional Local. Capítulo II, art. 29-35; Capítulo v, art. 38-41; Capítulo VI, art. 42-69; Capítulo vII, art. 70-72.
} 
Lo cierto es que la situación del país, que había heredado la crisis económica del Antiguo Régimen, junto a la propia inestabilidad inherente a todo régimen nuevo surgido de una revolución, a su vez iniciada por un pronunciamiento militar, no era propicia para ver cumplidos los deseos de los gobernantes. Máxime cuando algunos ayuntamientos se compusieron con personas afectas al Antiguo Régimen, por lo que unos meses después se publicó otra real orden para agilizar «con toda la brevedad posible» la activación de la Milicia Nacional en la forma prescrita y en todo el territorio nacional sin excusarse de verificarlo por carecer de armamento. ${ }^{17}$

En mayo de 1821 se daba un nuevo y definitivo reglamento, adicional al anterior. Básicamente disponía que los ayuntamientos pudieran recibir durante 4 meses como voluntarios a todos los que cumpliesen el reglamento estuvieran o no alistados en la Milicia Nacional. Pero los nuevos milicianos debían tener casa abierta, propiedad, rentas u oficio con taller para subsistir, o ser hijos del que tuviera esas circunstancias. Restringiendo las condiciones socioeconómicas al máximo para reforzar el carácter burgués y liberal de la milicia e, inferimos, evitar la infiltración de elementos populares y reaccionarios que dominaban algunas milicias locales. Además, también priorizaba el armamento de los voluntarios, más apegados en principio al nuevo régimen que los forzosos, en atención a la escasez de armamento. Solo en los casos en que no hubiera milicia voluntaria o en que su número no fuera suficiente para atender su cometido, la Diputación Provincial estudiaría la posibilidad de armar a la milicia legal. También introducía una nueva arma, la de artillería, y permitía que en los ayuntamientos donde se hubiera acordado unificar la Milicia Nacional Voluntaria y la Forzosa en un solo cuerpo, pudieran formar un único cuerpo de milicia reglada y considerada como voluntaria desde el inicio. ${ }^{18}$ En octubre el gobierno priorizaba a los pueblos cuyas circunstancias particulares exigieran «su más pronto armamento, prefiriendo los que absolutamente carecen de él», priorizando en todo momento a los cuerpos de voluntarios y «particularmente» a los milicianos liberales, esto es, a quienes «decididamente las empleen en asegurar y defender la Constitución política de la Monarquía, conservar la tranquilidad pública y perseguir a los malhechores ».19

\footnotetext{
17 Real orden de 2 de octubre de 1820.

18 Decreto de 4 de mayo de 1821 . Reglamento adicional al de 31 de agosto de 1820 para la Milicia nacional.

19 Orden de 31 de octubre de 1821.
} 
En 1822 se dieron otras órdenes que puntualizaron algunos aspectos como el modo de recibir el santo y seña durante las guardias, ${ }^{20}$ que la milicia de las plazas muradas no tomen las armas en tiempo de guerra sin permiso del gobernador de la plaza, ${ }^{21}$ que los soldados licenciados quedasen sujetos para el alistamiento de la milicia, ${ }^{22}$ suspender la venta de plomo y pólvora en las provincias españolas del País Vasco, Navarra, Aragón y Cataluña donde la contrarrevolución era más fuerte, y dar prioridad a la provisión de esos útiles a la Milicia Nacional. ${ }^{23}$ También se reguló el salario que recibían los milicianos cuando servían fuera del término municipal, que de 5 reales bajó al «prest íntegro» de los soldados por «la actual escasez de fondos».24

El cambio del gobierno moderado por uno más radical introdujo una nueva Ordenanza para regular la Milicia Local destinada a engrosar las milicias ante la mayor presión de las guerrillas realistas. Recogía la mayor parte del articulado de los reglamentos de agosto de 1820 y la adición de abril 1821, pero tenía derogaba todos los reglamentos y órdenes anteriores sobre el particular. Modificó algunos aspectos, pues, por ejemplo, obligaba al servicio de todo vecino de edad comprendida de entre 20-45 años, aunque admitía voluntarios a partir de los 18 años, con las restricciones socioeconómicas anteriores a las que sumaba específicamente a los criados, jornaleros y pastores. Decretaba que todos los nuevos milicianos reclutados serían considerados forzosos salvo que se presentaran voluntarios. También exceptuaba del servicio a los sacristanes en los pueblos donde solo hubiera uno. Si los empleados municipales querían servir debían hacerlo sin desatender su puesto y con el visto bueno del ayuntamiento. En cuanto a sus obligaciones, se priorizaba «sostener la Constitución política de la Monarquía promulgada en Cádiz en 19 de marzo de 1812, y restaurada en las Cabezas de San Juan en $1^{\circ}$ de enero de 1820 ». Además ponía a la milicia bajo la orden diaria y extraordinaria del alcalde primero o de su sustituto, no pudieron reunirse salvo en casos de alarmas, incendios o conmoción pública, avisando de que el servicio prestado debía ser el «absolutamente indispensable» pues «por su naturaleza debe estar exenta de demasiado fatiga, que la distraiga de sus ocupaciones

\footnotetext{
20 Orden de 11 de abril de 1822.

${ }^{21}$ Orden de 5 de mayo de 1822.

22 Orden de $1 .^{\circ}$ de mayo de 1822.

23 Orden de 16 de junio de 1822.

24 Orden de 23 de junio de 1822.
} 
ordinarias». ${ }^{25}$ Otra novedad que acompañaba al juramento era la entrega de la insignia estando sobre las armas con la siguiente exhortación:

Milicianos nacionales: todos los individuos tenemos la honra de estar alistados bajo de esta insignia nacional, que Dios nuestro señor se ha dignado bendecir para que nos sirva de punto de reunión contra los enemigos de nuestra independencia y de nuestra libertad civil; estamos obligados a conservarla y defenderla hasta perder nuestras vidas, porque así lo exige la gloria de la Nación, el crédito del cuerpo y nuestro propio honor, cifrado en el cumplimiento de la solemne promesa que hemos hecho de emplear las armas que la patria ha puesto en nuestras manos en defensa de la Constitución política de la Monarquía; y en fe y señal de que así lo prometéis: Batallón: preparen las armas, apunten, fuego. ${ }^{26}$

En cuanto a las recompensas, cualquier miliciano que se «inutilizare» en acto de servicio por combatir al enemigo y no tuviera bienes para mantenerse, recibiría una pensión vitalicia si lo aprobaban las autoridades políticas. Así como las viudas, hijos menores y padres de cualquier miliciano que falleciera en acto de servicio. Siendo los bienes de los sediciosos, ya fuera autores o cómplices, implicados en la muerte de un miliciano, los primeros usados para costear la pensión. ${ }^{27}$

El servicio era gratuito y la financiación pública, pero para contribuir al esfuerzo nacional todos los ciudadanos de entre 20 y 45 años que no fueran milicianos pero no estuviesen exceptuados, pagarían cinco reales mensuales. Salvo los jornaleros, sirvientes, pobres, militares en activo o retirados con sueldo menor de quinientos reales mensuales. ${ }^{28}$

En cuanto a la autoridad a la que quedaba sujeta la milicia, la ordenanza señala a los ayuntamientos en general y a la superioridad política municipal en particular. Si bien estos debían remitir informes sobre el estado de la fuerza y noticias sobre los servicios a las diputaciones. Igualmente, en cada pueblo se debía proporcionar un local para establecer el cuartel de la milicia. ${ }^{29}$

\section{La Milicia Nacional del Valle Medio del Ebro en el Trienio}

\subsection{Aragón}

25 Decreto CXXII de 29 de junio de 1822. Ordenanza para la Milicia local. Título I, art. 1-9; Título IV, art. 61-85.

${ }^{26}$ Ibídem. Título v, art. 91.

27 Ibídem. Título vIII, art. 142-152.

28 Ibídem. Título IX, art. 153, 155, 161 y 162.

29 Ibídem. Título X, art. 166-171; Disposiciones transitorias, art. 178. 
El triunfo liberal aragonés en el Trienio antecede al juramento constitución del rey Fernando VII. Días antes de producirse este hecho en Zaragoza se proclamó la Constitución de 1812.30 Levantando un cuerpo de Guardia Cívica - que cesará entre el verano y el otoño de 1820- para garantizar el orden público liderado por ilustres liberales, aunque integrado parcialmente por absolutistas, que ya habían combatido durante la Guerra de la Independencia (Sorando y Manzano, 2000, 178). El mismo impulso erigirá en abril de 1820 una Sociedad Patriótica, al tiempo en que se organizó la instauración de la Milicia Nacional (un batallón de infantería y una compañía de caballería) conforme al reglamento de $1814 .{ }^{31}$ Este cuerpo, totalmente sujeto al liberalismo, actuará junto al Ejército y simpatizantes para reducir el levantamiento realista producido en Zaragoza en el mes de mayo (Rújula, 2000, 54 y ss.).

El ejemplo de la capital maña cundió en otros municipios y la villa de Sos proclamó la Constitución tres días después, disponiendo para finales de noviembre de un batallón de Milicia Nacional al grito de «Constitución o muerte». Sus oficiales dijeron que «si en las Termopilas murieron trescientos espartanos por obedecer las leyes, Sos tiene dispuestos a morir 554 españoles de que consta su batallón de milicias por conservar las leyes fundamentales del Estado».32 Mientras tanto, recibido el reglamento de agosto de 1820, la Milicia Nacional Local de Zaragoza pasaba a ser Milicia Nacional Voluntaria y con el reclutamiento de la milicia legal formaban cinco batallones de infantería y un tercio de caballería. Reducidos en enero de 1821 por su escasa fuerza (un total de 2320 hombres) a un batallón de infantería y una compañía de caballería voluntarios y 5 de infantería y un tercio de caballería forzosa (Sorando y Manzano, 2000, 182-184).

Esta milicia logra entre 1820-1821 frenar las insurrecciones aragonesas ante la indiferencia y la apatía de los ayuntamientos (Arnabat, 2001, 14), de ahí que la opinión pública se divida entre el liberalismo militante de la milicia, el moderantismo parcialmente «retardado» de las autoridades y el realismo claro de los absolutistas, y que se produzcan diferencias entre los milicianos y los ayuntamientos (Rújula, 2000, 84), que son aprovechados por los realistas para atacar el régimen constitucional y a los milicianos, principales valedores. Estas desavenencias se notan en septiembre de

\footnotetext{
${ }^{30}$ El Universal, $1 .^{\circ}$ de diciembre de 1820, p. 2.

${ }^{31}$ Diario Constitucional de Zaragoza, 23 de abril de 1820.

${ }^{32}$ El Universal, 1 de diciembre de 1820, p. 2.
} 
1821 cuando la autoridad prendió a un oficial voluntario y otro fue comisionado para informar a Riego de su destitución como capitán general de Aragón. Si bien los milicianos acataron las órdenes también intentaron, sin éxito por la negativa política, manifestar públicamente la inocencia del héroe del Trienio. Le habían nombrado como «su coronel» y le siguieron en abril hasta Pamplona para combatir la contrarrevolución (VV.AA, 1821, 12, 16 y 23). Y a finales de octubre cuando un levantamiento exaltado apoyado en la Milicia Nacional deriva en la dimisión del Jefe Superior Político33, pero unos milicianos son atacados y desarmados en Zaragoza por vecinos absolutistas (Lafuente, 1888, 323).

Aprovechando un nuevo alistamiento de la Milicia Nacional Voluntaria en Zaragoza en mayo de 1821, se dejó sentir más la influencia moderada del ayuntamiento. El proyecto de crear un segundo batallón miliciano produjo que buena parte de los milicianos forzosos quisieran pasarse al servicio voluntario. Incluso todo un batallón, a quien no se le permitió el cambio, siendo la fuerza voluntaria la que demostraba su compromiso político dentro y fuera de Zaragoza participando en las expediciones a Gelsa (Zaragoza) y Tudela (Navarra) para combatir a las fuerzas realistas en 1821. Y la fuerza miliciana permitía operar así, pues contaba con unos 2.200 hombres distribuidos en dos batallones de infantería, una compañía y un tercio de caballería y una compañía de artillería voluntaria más 5 batallones de infantería y una escuadra de caballería legal. Las autoridades decidieron, aprovechando el trasvase de milicianos, reducir a dos los batallones de infantería forzosa y comenzar a desarrollar una Milicia Cívica que se encargase de la vigilancia municipal con la Milicia Nacional (Sorando y Manzano, 2000, 185-188), reduciendo así la operatividad de la milicia voluntaria.

Los enfrentamientos entre milicianos y vecinos que se dan entre otoño y diciembre de 1821 en Zaragoza tuvieron su correlato en varios pueblos de la provincia y de la región. 34 En todos los casos los voluntarios fueron atacados entre vivas a la Constitución y a la religión de unos, y mueras a los milicianos de otros, llegando las autoridades a justificar parcialmente a los vecinos realistas sobre la base de las provocaciones que los milicianos les hacían, o hacían contra el clero por instigar los levantamientos realistas. Pero los milicianos denunciaban a los absolutistas como

33 Diario Constitucional de Zaragoza, 5 de noviembre de 1821.

34 Ibídem. 22 de julio, 5 de noviembre y 15 de diciembre de 1821. 
principales impulsores del enfrentamiento y al ayuntamiento por su pasividad para reprimirlos y dejar desampara a la Milicia Nacional. Como ocurre en Huesca, donde se produjo un motín anticonstitucional y el ayuntamiento desarmó a los milicianos voluntarios ante la pasividad de la milicia forzosa. Solo la intervención de tropas llegadas desde Zaragoza frenó la insurrección realista. Ocurre en otras localidades como Bellestar, Igriés y Angüés (Rújula, 200o, 85-90).

En 1822 la guerra civil y la insurrección avanzó por España y la milicia zaragozana se dedicaba en funciones defensivas, siendo el Ejército el encargado de salir hacia Cataluña para combatir a los realistas. La milicia quiso combatir, pero las autoridades les relegaron a un papel policial, lo que no evitó que pudieran auxiliar a las milicias y autoridades de otros puntos de Aragón, como Calatayud, cuando fue invadida por una partida y tuvieron que recuperar la ciudad, o Alcampel (Huesca) de donde volvieron victoriosos, llegando a participar en otras acciones en territorio aragonés y navarro como Nuez, Gelsa, Pina de Ebro, Villafranca y Beceite (Sorando y Manzano, 190-192). Asimismo, otras milicias destacadas fueron las de Calanda, Alcañiz y Caspe, que a duras penas trataron de contener los levantamientos realistas, siendo los principales blancos de la furia absolutista cuando se producían motines locales o la guerrilla entraba en una población, y que sobre todo encontraron apoyo en el Ejército cuando terminó con esos actos acusando a las autoridades de no atacar con la insurrección de manera determinante (Rújula, 2000, 72-78). También las milicias de Alcañiz, Calanda, La Ginebrosa, Caspe y Villalba refuerzan al Ejército cuando la guerrilla se apodera de Horta, mientras que algunos ayuntamientos y poblaciones por donde transitaban las fuerzas absolutistas, sobre todo en la provincia de Huesca, colaboraban con ellas, siendo sus milicias insuficientes para contener las invasiones. En tales casos las milicias no dudaban en acudir a otro punto para ayudar al Ejército a combatir la insurrección, como la Milicia Nacional de Albarracín, que no pude evitar la toma de su pueblo pero ayuda a derrotar a la reacción en Bronchales (Rújula, 2000, 107-120).

A finales de 1822 las tropas realistas atacan Teruel, que es bien defendida y donde la autoridad provincial destacó el arrojo de su milicia. También en Malón unos soldados y las milicias de Buñuel, Pozuelo y Tabuenca logran detener el avance de la 
guerrilla (Rújula, 2000, 150-151).35 A principios de 1823 Zaragoza es atacada a gran escala por el Ejército Realista, siendo la ciudad defendida con éxito por su guarnición y milicia. Solo cuando la ciudad se vio amenazada por el Ejército francés que vino en auxilio de las tropas realistas españolas, buena parte de la milicia nacional abandonó Zaragoza para unirse al Ejército y combatir en Levante y Andalucía donde terminaron su servicio (Sorando y Manzano, 2000, 195-196).

\subsection{La Rioja}

El triunfo de la revolución de 1820 en La Rioja vino después de la sanción del rey. Pese a ello, los liberales fueron muy activos en Logroño y en otras localidades importantes como Santo Domingo de la Calzada y Haro, intentando establecer la Milicia Nacional voluntaria inmediatamente. En mayo el ayuntamiento de Logroño trató la cuestión tras recibir el decreto de la Junta Provisional ${ }^{36}$, medida apoyada por la Sociedad Patriótica de la ciudad, compuesta por la elite sociopolítica local, cuyos socios estaban dispuestos a «derramar su sangre en defensa de la religión y de la patria» y en defensa de las libertades constitucionales. Presentó al ayuntamiento una lista de milicianos voluntarios que serían liderados por el comandante de armas de Logroño, un ilustre liberal, pidiendo que el ayuntamiento hiciese pública la noticia para animar a otros vecinos a seguir su ejemplo.37 Las medidas fueron descartadas por el poder local exponiendo distintos inconvenientes y reparos ${ }^{38}$ que no desanimaron a los patriotas logroñeses, los cuales insistían en la necesidad de formar la Milicia Nacional voluntaria para una mejor defensa del pueblo y de sus derechos. 39 En verano, el comandante propuesto por los patriotas lideró a los voluntarios logroñeses para sofocar la acción de los realistas castellanos en la sierra de los Cameros, junto a voluntarios de otros pueblos comarcanos. Tras ese hecho el ayuntamiento de Logroño se reunió con los patriotas y accedió a publicar el alistamiento de la Milicia Nacional y a encargarse del reclutamiento de voluntarios, si bien su éxito fue escaso..$^{40}$ No fue hasta recibir el primer reglamento del Trienio, que establecía la obligación del servicio, cuando la

\footnotetext{
35Diario Constitucional de Zaragoza, 11 de setiembre de 1822.

36 Archivo Municipal de Logroño (AML). Libros de acuerdos de 1819-1820, 13 de mayo de 1820.

37 AML, Libros de acuerdos de 1819-1820, 27 de mayo de 1820.

${ }^{38}$ AML, Libros de acuerdos de 1819-1820, 27 de mayo de 1820.

39 Ibídem 26 de julio de 1820.

40 Ibídem, 2 y 5 de agosto de 1820.
} 
Milicia Nacional de Logroño se formó con un batallón y siete compañías de infantería y un tercio de caballería. 41

En otros puntos de la región como Santo Domingo de la Calzada fueron los notables liberales quienes suplieron la carencia de una Sociedad Patriótica. Liderados por el alcalde constitucional lograron que el ayuntamiento aprobase la creación de la Milicia Nacional a mitad de julio reuniendo rápidamente una fuerza de 44 milicianos e informando a la autoridad superior. ${ }^{42}$ En cambio en Calahorra, al otro extremo de la región, el cambio político fue dirigido por la conservadora elite del Antiguo Régimen y la seguridad de la ciudad fue encargada inicialmente al Ejército, hasta que la creación de un cuerpo local de milicia de 30 efectivos más sus oficiales lo suple en la primavera de 1821.43

Hasta 1821 la milicia riojana no actuó fuera de sus demarcaciones y se emplearon sobretodo en mantener el orden local. A partir de entonces su actividad se incrementó notablemente sobrepasando el ámbito municipal. Especialmente las de Logroño, Santo Domingo y Haro, destacando la primera por combatir el levantamiento realista en Salvatierra (Álava) en abril. Allí se desplazaron 113 milicianos, 22 de los cuales habían sido miembros de la Sociedad Patriótica de Logroño, previa autorización del ayuntamiento. La actividad miliciana de esta ciudad es fiel reflejo de su firme compromiso con la revolución, siendo más de la mitad de los oficiales reputados patriotas. Tenía buena sintonía con el ayuntamiento. Uno de los jefes de la milicia que acude al combate de Álava era el alcalde segundo de la ciudad, y el primer alcalde también era miliciano.44 La de Calahorra se mantenía ocupada en patrullar calles los campos en busca de absolutistas que aprovechaban el amparo de las noches de otoño para realizar actos subversivas y atacar a los vecinos liberales y sus propiedades. 45

El celo demostrado por la milicia de Logroño derivó en enfrentamientos con la autoridad local. En diciembre de 1821 los realistas navarros habían llegado a Lodosa

\footnotetext{
${ }^{41}$ Ibídem, 14, 17 y 26 de octubre de 1820; 17 de octubre de 1820.

42 Archivo Municipal de Santo Domingo de La Calzada (AMS), Libro de acuerdos de 1820, 17 de julio de 1820.

43 Archivo Municipal de Calahorra (AMC). Libro de actas municipales. Sig. 135/7. 5 de abril de 1821.

44 AML, Libro de acuerdos de 1821, 9 de junio de 1821 y 1 de octubre de 1821. El Universal, 18 de febrero de 1821.

45 AMC, Libro de actas municipales, sig. 135/7. 17 de abril de 1821; 11 y 15 de octubre de 1821.
} 
(Navarra) y se mandó establecer un pequeño retén nocturno para contenerlos en la otra orilla del Ebro. Los mandos de la milicia querían atacarles en vez de defender la posición, lo que degeneró en desconfianzas mutuas entre el ayuntamiento, más moderado, y la milicia local, más exaltada. ${ }^{6}$ En junio de 1822 la presión del realismo navarro comienza a cercar La Rioja por ambas orillas tomando posiciones en Lodosa (Navarra) y Alcanadre y los milicianos volvieron a pedir que les dejasen salir a su encuentro. Las autoridades dejaron partir a unos 90 hombres siendo sonada la victoria que infringieron a los absolutistas cerca de Los Arcos (Navarra). 47 En verano la guerrilla llegó hasta Viana (Navarra), acercándose los absolutistas prácticamente a las puertas de Logroño, pero no se permitió salir a la Milicia. Esto generó nuevos enfrentamientos y avivó el malestar anterior porque los milicianos, dispuestos a «perecer combatiendo», quisieron salir a luchar, pero las autoridades pensaban que eran necesarios para guardar la ciudad. Finalmente se les dejó hacer una misión de reconocimiento hasta Moreda que confirmó el peligro real que se cernía sobre Logroño y La Rioja. Cuando esa información llegó a la tropa, tras pasar por el ayuntamiento, los enemigos habían huido aumentando el malestar entre los milicianos. ${ }^{8}$ La Milicia Nacional de Logroño, liderada por liberales radicales, se había colocado a la vanguardia del constitucionalismo riojano, coincidiendo con la militancia comunera del comandante de la milicia y del comandante de armas de la ciudad, lo cual tensó más la relación con el ayuntamiento hasta el punto de llegar a criticar duramente la actitud moderada de la autoridad local que terminó con la censura y destitución de algún oficial en 1823.49

La fama de la milicia logroñesa había traspasado fronteras y cuando en el verano de 1822 la guerrilla navarra atacó la zona oriental de La Rioja, 120 milicianos fueron autorizados a salir voluntariamente hacia Calahorra previa petición de auxilio de los ayuntamientos de Calahorra y Alfaro al Jefe Político de Logroño, aunque el ayuntamiento de Logroño prefería pedir al gobierno más fuerza militar.5o En septiembre las fuerzas realistas atacaron Santo Domingo de la Calzada con cuatrocientos hombres, pero no pudieron tomarla por la ayuda llegada desde Haro

\footnotetext{
${ }^{46}$ AML, Libro de acuerdos de 1821, 14, 17, 21 y 28 de diciembre de 1821.

47 AML, Libro de acuerdos de 1822, 1 y 5 de junio.

48 AML, Libro de acuerdos de 1822, 3 de agosto.

49 AML, Libro de acuerdos de 1822, 24 de octubre; Libro de acuerdos de 1823, 31 de marzo.

${ }^{50}$ AML, Libro de acuerdos de 1822, 2 de agosto.
} 
(cincuenta soldados y cincuenta milicianos) y desde Logroño (un batallón de 120 milicianos) que resistieron junto a los treinta milicianos calceatenses y los cincuenta soldados de la guarnición local. ${ }^{11}$ Incluso en la ribera navarra destacaron los milicianos de Logroño que eran recibidos por los liberales como «beneméritos patriotas» cuando ayudaron a los milicianos de Cascante, Tudela y Corella finalizar con los levantamientos realistas (Idoate, 1966, 288).

La milicia de Santo Domingo de la Calzada se batió contra la fuerza dirigida por el guerrillero Ignacio Alonso Cuevillas, quien hostigó en 1821 y 1822 las comarcas de Haro, Santo Domingo y Nájera. Huyó hacia Burgos para escapar de la persecución de las milicias riojanas perfectamente coordinadas. $5^{2}$ Por su parte la milicia calagurritana formó en el verano de 1822 una red de seguridad con la milicia de Cervera del Río Alhama cuando «una banda de facciosos» entró en Lodosa (Navarra), dando avisos a otros ayuntamientos próximos y siendo reforzada por la milicia logroñesa.53 No impidió el saqueo de Alfaro y la captura de su alcalde, pero sí logró poner en fuga a los realistas. La situación no era fácil pues por un lado debían vigilar el sur de la región y por el otro la línea del Ebro, ya que ambos puntos estaban amenazados. Si bien la segunda línea fue traspasada una vez, la primera resistió bien y las milicias contuvieron una partida cuando intentó cruzar de Navarra hasta La Rioja. Ante la amenaza de que atacasen por las dos zonas simultáneamente, también recibieron apoyo del batallón de milicias de Burgos, 54 lo que permitió que las milicias de Arnedo, Quel, Calahorra y otros municipios cercanos derrotasen a la facción de Elvira en octubre. No les persiguieron cuando los realistas abandonaron los límites comarcales por orden del ayuntamiento, siendo criticado por ello por la autoridad política provincial que les exigió el exterminio de los enemigos.55 Pese al esfuerzo de proteger el territorio, no pudieron impedir que un cuerpo de voluntarios realistas navarros liderados por Landívar, comisionado de la Junta Realistas de Navarra, atacase Calahorra con más de 400 efectivos. Cuando la ciudad se vio libre de nuevo, el ayuntamiento ordenó que tanto sus miembros como los liberales ayudasen en las tareas de vigilancia y defensa junto a la milicia local.56 A mitad

\footnotetext{
${ }^{11}$ El Espectador, 22 de noviembre de 1822, p. 920.

52 Archivo Catedral de Santo Domingo de La Calzada (ACSDC), Fondo Chacón-Múgica, leg. 31/59 y 31/76.

53 AMC, Libro de actas municipales, sig. 135/8, 13 de junio de 1822 y 8 de agosto de 1822.

54 Ibídem, 20 de agosto de 1822 y 12 de setiembre de 1822.

55 Ibídem, 6 de octubre de 1822.

${ }^{56}$ Ibídem, 26 y 30 de octubre de 1822.
} 
de agosto de 1822 la Diputación Provincial de Logroño destacó el entusiasmo, valor y arrojo con que las milicias riojanas combatían a los realistas en su provincia. 57

\subsection{Navarra}

El triunfo liberal en Pamplona se adelanta, como en Zaragoza, a la Corona. ${ }^{8}$ Después lo verificarían otras ciudades como Tudela al tiempo en que el cambio político se produce en La Rioja.59 En Navarra las autoridades difieren en materia política. Al moderantismo del gobierno provincial se opone el realismo del primer ayuntamiento pamplonés, solución que no satisface a los exaltados de las sociedades patrióticas de Pamplona o de Tudela ni a los absolutistas y que tiene su correlato en la creación de la Milicia Nacional de Pamplona donde todos infiltran a sus partidarios (Del Río, 1987, 40-41). Salió triunfal el criterio municipal para crear una Milicia Nacional voluntaria con meras funciones de guardia contra la pretensión liberal de que la fuerza se ocupe de conservar el orden político. La milicia de Pamplona, con un total de setecientos efectivos, se organiza en un batallón de cinco compañías de infantería y un tercio de caballería. Se compone de propietarios y artesanos, burgueses liberales, pero el cuerpo está trufado de realistas alistados para eliminar o disminuir el carácter revolucionario de la fuerza miliciana,6o a diferencia de la Milicia Nacional legal formada por un batallón de seis compañías (unos 470 hombres) dominada por los liberales (Garralda, 1988 320-323; Herrero, 2003, 185).

En Tudela se decidió reponer los priores de barrio o de cuartel, una suerte de milicia absolutista local, para encargarse de la tranquilidad y seguridad pública en apoyo de los mayorales. Una medida que el ayuntamiento juzgó compatible con la Constitución y con las necesidades urgentes de la ciudad. ${ }^{61}$ Para agosto ya se había formado un tercio voluntario de Milicia Nacional liderado por personajes ligados con el ayuntamiento y con la Sociedad Patriótica local ${ }^{62}$, pese a que contase con más apoyo entre los patriotas que entre los regidores, como lo demuestra la separación que se hizo entre el papel de los patriotas y el papel de la autoridad local para que la segunda gozase

\footnotetext{
57 ACSDC, Fondo Chacón-Múgica, leg. 31/o1.

${ }_{58}^{8}$ Correo general de Sevilla, 22 de marzo de 1820.

59 Archivo Municipal de Tudela (AMT), Libro de acuerdos de la ciudad de Tudela, n. ${ }^{\circ} 20$.

6o Sobre todo, entre la infantería. No así en la caballería ni en la artillería.

${ }^{61}$ AMT, Libro de acuerdos de la ciudad de Tudela, n. ${ }^{0} 20$, f. $25 \mathrm{v}$.

${ }^{62}$ Ibídem, 55v.
} 
de autonomía.63 En otoño de 1820 se comenzó el reclutamiento forzoso de la milicia y para enero de 1821 se terminaba de formar un cuerpo de infantería y de caballería igualmente representativo de los liberales tudelanos, que ofrecieron «animados del mejor espíritu» sus servicios a la corporación municipal «a toda hora que el Ayuntamiento gustase valerse de ellas para el servicio nacional» y recibiendo las gracias del poder local que «oyó con agrado los buenos sentimientos» de la milicia. 64

En general y más allá de algunos enfrentamientos producidos en Pamplona y Tudela entre la milicia y los vecinos realistas, la primera prueba de fuego para la milicia navarra tuvo lugar en abril de 1821 merced a los levantamientos realistas alaveses. La milicia pamplonesa recluta en torno a un centenar de voluntarios, mayormente liberales, para combatir en Salvatierra (Álava) (Garralda, 1988, 322-323). La milicia de Tudela manifiesta «su entusiasmo y deseo de que en caso necesario se les ocupe contra los facciosos en el punto de mayor peligro», al tiempo en que el ayuntamiento les informa que serán armados de inmediato y que «podrían llegar tropas de Zaragoza» para reforzarles. 65 Gracias a ese apoyo los milicianos de Tudela combatieron en las acciones de Salvatierra y Ochandiano (Idoate, 1966, 282). La victoria liberal fue causa del enfrentamiento de la milicia con los vecinos realistas cuando volvieron a la ciudad y celebraron su triunfo. Sabedor el ayuntamiento de «la total derrota y entrega a nuestras tropas de los facciosos» determinó que se celebrase una misa «en acción de gracias al Todopoderoso» en la catedral. A los vivas a la constitución que daban los liberales se respondía con vivas a la religión por los realistas. ${ }^{66}$

En enero de 1821 se produjo en Tudela un enfrentamiento entre paisanos absolutistas y milicianos causado por los himnos patrióticos que cantaban en sus rondas nocturnas. La milicia se paraba para cantar frente a las viviendas de los realistas, produciéndose un motín absolutista que desembocó en la persecución de los liberales. El alcalde calmó los ánimos y denunció la provocación que hacían los milicianos, lo que vició la relación de la milicia con el ayuntamiento y de este con la jefatura provincial. Los patriotas llegaron a denunciar que el alcalde había encabezado

\footnotetext{
63 Ibídem, 35.

64 Ibídem, 72, 92v y 93.

65 Ibídem, 113 v y 114.

66 Ibídem, 116.
} 
a la turba realista y que su tibieza era síntoma de reacción. ${ }^{67}$ Esta diferencia de pareceres también se visibilizó en septiembre cuando llegaron ecos de la destitución de Riego en Zaragoza. La milicia se ofreció al ayuntamiento para salir a defender con las armas los intereses de la patria, pero se les denegó el permiso (Del Río, 1987, 69). 12 milicianos forzosos decidieron entrar al servicio voluntario y 18 vecinos pidieron ser admitidos voluntarios. ${ }^{68} \mathrm{El}$ ayuntamiento estableció la Guardia Cívica con el fin de controlar la epidemia de fiebre amarilla que podía llegar desde Cataluña y las entradas y salidas de la población.69

Una tesitura similar se produce en Pamplona para octubre de 1821. Ante los enfrentamientos que se dan entre la tropa liberal y los vecinos realistas, el ayuntamiento impone una Guardia Municipal en compañía de la Milicia Nacional. Episodios de violencia contra el pueblo absolutista se producen en otros municipios como Corella, donde la milicia reprime con las armas los ataques, a diferencia de Pamplona. El ayuntamiento pidió el auxilio de la milicia tudelana que no se verificó porque su corporación respondió que no podía enviarla sin aprobación superior. Solo la llegada del Ejército y su combinación con la milicia de Corella terminó con el motín. Lo mismo ocurrió en Viana. En cambio, cuando se produzcan mayores levantamientos realistas en las merindades de Tudela y Sangüesa a finales de año, la actuación del Ejército y las milicias de Tudela y Corella derrotarán a la guerrilla absolutista, verificando así la utilidad y ardor revolucionario de la milicia local navarra (Del Río, 1987, 75-77 y 81-82).

Para 1822 los enfrentamientos entre liberales y realistas hacían la situación insostenible para el moderantismo del poder político. Como ocurrió en Tudela en enero cuando se celebró la victoria «contra los facciosos» de diciembre anterior. Primeramente el ayuntamiento se negó a celebrar un banquete. En su lugar, dispuso una misa en la catedral a la que a la milicia local le acompañaron milicianos de otros puntos de Navarra, La Rioja y Aragón como Borja, Tarazona, Tafalla, Cintruénigo, Cascante, Margallón, Ainzón, Cervera y Murchante. En mitad del oficio los vecinos realistas comenzaron a gritar e insultar porque el capellán de los milicianos alabó en el sermón la virtud de los voluntarios, teniendo que intervenir el obispo de Tudela e

\footnotetext{
${ }^{67}$ Archivo General de Navarra, Guerra, leg. 23, c. 1. Cit en: Gambra, 66 y Del Río, 59.

68 AMT, Libro de acuerdos de la ciudad de Tudela, $\mathrm{n}^{0} 20$, f. 129v, 130, 138v y 139.

69 Ibídem, 183v.
} 
improvisarse otro sermón distinto para calmarlos. A la salida de la catedral y ante la afrenta recibida, los milicianos formaron en la plaza de la Constitución pidiendo «la cuchilla de la ley» contra los «criminales bárbaros» (Laborie, 1968, 89). También los militares que operaban en Navarra pidieron el desarme de la milicia pamplonesa por estar llena de enemigos, denunciando el hostigamiento que allí sufrían los milicianos liberales y los soldados, medida apoyada por la milicia de Tudela, ante lo que el gobierno decidió militarizar la plaza y desarmar la milicia voluntaria de Pamplona, para enojo de los milicianos liberales de Pamplona que habían combatido en Álava en 1821 (Del Río, 1987, 98-99 y 101).

$\mathrm{Y}$ es que muchas veces los milicianos eran los únicos valedores del régimen constitucional. Sobre todo en los pueblos como Muchante, donde en el verano de 1822 estalló un motín realista y los milicianos respondieron con fuego. El alcalde decidió desarmarlos y detener a los liberales más exaltados hasta que llegó la milicia de Tudela y forzó su libertad sin poder tomar el municipio en manos de los absolutistas que les increparon. Solo la llegada de otras milicias navarras y aragonesas, un total de 450 hombres, logró reponer el orden constitucional. O como en Cascante, donde se acusó al ayuntamiento de ser cómplice de los realistas y los vecinos realistas aprovecharon la salida de la milicia para combatir en Álava y otros puntos de Navarra, para desarmar al resto de la milicia e iniciar un motín anticonstitucional que fue recuperada con la ayuda de la milicia de Logroño (Laborie 1968; Idoate, 1966, 287-288). Ante el incremento de la presión reaccionaria, los liberales de Tudela temieron perder la ciudad por la falta de iniciativa de las autoridades municipales. Llegaron a denunciar que se les apartase del servicio mientras los absolutistas se adueñaban de la comarca y que se prefiriese esperar al Ejército para combatir donde no le necesitaba -en Tudelaen vez de mandarles a Cascante, Corella y Fustillana donde las milicias locales habían sido derrotadas por los realistas. Lamentaron que se tratase a los milicianos como «atropelladores de las autoridades» cuando habían dejado «sus hogares a la primera noticia de la Patria peligra». Asimismo, expusieron las vejaciones a las que sometían a los liberales en Tudela, tanto en las elecciones como después, donde se expulsaba a los regidores de los plenos en que se trataba sobre la Milicia Nacional por ser uno miliciano y otro padre de un miliciano (Del Río, 1987, 110-115).

Los temores de invasión de los liberales tudelanos estaban bien fundados. Mientras que la milicia local avisó a las de Cascante, Murchante y Cervera para que 
estuviesen alerta, comprobaron el peligro que se cernía en esa parte de la ribera del Ebro cuando llegaron a Alfaro y supieron que la guerrilla había entrado en la ciudad y apresado a su alcalde. Eso les espoleó al punto de decir que «aunque la patria sucumba, este puñado de valientes ha de morir matando». Pero también les indignó, porque las autoridades no les proporcionaron caballos y llegaron tarde, exclamando que si morían sería «en fuerza de sacrificios por un gobierno de quien no recibieron algunos». Mientras tanto en Tudela el ambiente se enrarecía e incluso se produjo alguna agresión de un grupo de vecinos contra un miliciano. Aunque la gota que colmó el vaso fue el ataque que sufrió Tudela por una partida de 650 hombres que habían ido conformándose con guerrillas navarras y aragonesas, y que fue repelida por la resistencia de los milicianos y la llegada de refuerzos desde Soria. Pasado el ataque los milicianos y sus familias buscaron refugio en Zaragoza, volviendo tiempo después junto a tropas aragonesas que reforzaron la ciudad, si bien en Tudela el compromiso liberal siguió siendo alto y se levantó una nueva compañía de milicianos ante la ausencia de los primeros (Gambra, 1972, 110-111; Idoate; 1966 289-290; Del Río, 1987, 240-247).

Solo entonces los milicianos comenzaron a tomar la justicia de su mano, exigiendo los suministros a los ayuntamientos que no los entregaban como pasa en Cascante con la milicia de Borja, llegando a amenazar en Tudela con actuar como si se tratase de un cantón militar si el ayuntamiento no atendía sus demandas de pertrechos, acuartelamiento y pagas. La situación terminó cuando el general Torrijos llegó a Tudela e hizo un llamamiento a los milicianos y ciudadanos para luchar por la Constitución juntos, si bien las autoridades municipales fueron señaladas por los liberales como desafectas hasta el final del Trienio.

\section{Conclusiones}

La creación del Estado nacional español se sostuvo por un cuerpo militar al servicio del poder civil centralizado, articulado en demarcaciones provinciales y municipales. Fue imprescindible para ello la Milicia Nacional porque asumía que los ciudadanos debían servir a la defensa de la nación prescrita en la Constitución de 1812. No solo defendían el territorio, a sus vecinos y las propiedades, sino el orden político. Su vinculación ideológica los llevó a defender otros pueblos, otras vidas y otras propiedades ajenas vertebrando de ese modo al propio Estado liberal. Sobresalieron los milicianos 
voluntarios más radicales a medida que las autoridades hicieron gala de un pensamiento más moderado.

En general, los milicianos fueron la burguesía revolucionaria, razón por la que se excluyó del servicio a las capas populares inferiores. Sus cánticos así como su mera presencia originaron enfrentamientos municipales por la existencia de capas locales reaccionarias que trataron de dificultar el cambio de régimen, lo que también derivó en el choque con los ayuntamientos. Los milicianos fueron más expeditivos ante el rechazo del orden constitucional y las autoridades, más conservadoras, prefirieron asegurar el orden público antes que terminar con la contrarrevolución.

Con independencia del criterio municipal, la Milicia Nacional sirvió para vertebrar y articular el propio Estado, siendo un símbolo que representó a nivel local a la ciudadanía en armas de todo el territorio nacional. A medida que se produjeron insurrecciones realistas, se comprometieron más con su misión política nacional que con su consideración local. Fue más visible entre los voluntarios que entre los forzosos.

La legislación que se generó en el Trienio muestra la divergencia de planteamientos políticos liberales. En general introduce una garantía de eficacia al considerar la milicia como una fuerza armada cívica que combina la preparación militar con la actividad privada, para que sirva en caso de necesidad dentro del lugar de residencia a las órdenes de oficiales elegidos por ellos en defensa del orden público constitucional. Erró cuando consideró únicamente el servicio voluntario, siendo necesario obligar al reclutamiento para erigir un cuerpo local de milicia en cada municipio, lo que a su vez ocasionó la inclusión de absolutistas.

La milicia fue también un modo de tomar el pulso político de los pueblos y ciudades durante el Trienio porque intervino en los principales hechos de armas locales, regionales y provinciales. Mostró la lucha interna entre liberales, pero también contra elementos reaccionarios que intentaban controlarla para obstaculizar la progresión del Estado constitucional. En ocasiones fue el único apoyo que el liberalismo tuvo de manera evidente en algunos de los espacios analizados, sobre todo en el ámbito rural y en pueblos pequeños. Fue, en resumen, la fuerza activa de la burguesía para intervenir en la política y ampliar la participación política a otras capas sociales distintas a la oligarquía absolutista y a la proto-oligarquía liberal, de ahí que 
los liberales radicales quisieran armar solo a los voluntarios, usar la milicia como fuerza auxiliar del Ejército sujeta al poder municipal permeado por los patriotas, y ser la patria armada que soñaron y diseñaron los liberales revolucionarios.

\section{Obras citadas}

\subsection{Fuentes}

Archivo Catedral de Santo Domingo de La Calzada, Fondo Chacón-Múgica.

Archivo General de Navarra, Guerra.

Archivo Municipal de Calahorra. Libro de actas municipales. Sig. 135/7 y 135/8.

Archivo Municipal de Logroño, Libros de acuerdos de 1819-1820, 1821, 1822 y 1823.

Archivo Municipal de Santo Domingo de la Calzada. Libro de acuerdos de 1820.

Archivo Municipal de Tudela. Libro de acuerdos de la ciudad de Tudela, $\mathrm{n}^{0} 20$.

Colección de los Decretos y órdenes generales de la primera legislatura de las Cortes ordinarios de 1820 y 1821 . Desde 6 de julio hasta 9 de noviembre de 1820, t. VI (Madrid: Imprenta Nacional, 1821).

Colección de los decretos y órdenes generales expedidos por las Cortes desde $1^{\mathrm{o}}$ de marzo hasta 30 de junio de 1822, t. IX (Madrid: Imprenta Nacional, 1822).

Colección de los Decretos y Reales Órdenes, que se han expedido o circulado por la secretaría del Despacho de la gobernación de la península, correspondientes a los años de 1820 y 1821 (Madrid: Imprenta Nacional, 1822).

Constitución Política de la Monarquía española (Cádiz, 1812).

Correo general de Sevilla.

Decreto LXXIII de 15 de abril de 1814. Reglamento para la Milicia Nacional (Las Cortes, 1814).

Diario Constitucional de Zaragoza.

El Espectador.

El Universal.

\subsection{Bibliografia}

Arnabat, Ramón, La revolució de 1820 i el Trienni Liberal a Catalunya (Vic: Eumo, 2001).

Artola, Miguel, «La Monarquía parlamentaria», Ayer, 1 (1991): 105-124.

Blanco, Roberto L., Rey, cortes y fuerza armada en los orígenes de la España liberal, 1808-1823 (Valencia: IVEI, 1988).

Calles Hernández, Claudio, La Milicia Nacional en Salamanca durante el Trienio Liberal (1820-1823) (Salamanca, Universidad de Salamanca: 2015). 
Cañas Díez, Sergio, Crisis del Antiguo Régimen y liberalismo en Calahorra (La Rioja) 1788-1840 (Logroño: Universidad de La Rioja, 2016).

Casado, Pablo, Las fuerzas armadas en el inicio del constitucionalismo español (Madrid: Editoriales de Derecho Reunidas, 1982).

Casals, Quintí, «Milicia Nacional, Liberalismo y Progresismo. El prototipo leridano en los primeros dos tercios del siglo XIX», Trienio, 35 (2000): 117-154.

Castro, Concepción de, La revolución liberal y los municipios españoles (1812-1868) (Madrid: Alianza, 1979).

Codesal, Matilde, La ciudad de Zamora en el Trienio Liberal (1820-1823): conflictividad sociopolítica en un contexto de crisis (Zamora: Ayuntamiento de Zamora, 2008).

Díez Morrás, Francisco Javier, Los inicios del constitucionalismo en La Rioja. El Trienio Liberal (1820-1823) (Logroño: Universidad de La Rioja, 2019).

Chust, Manuel y Serrano, José Antonio, «Milicia y revolución liberal en España y en México». Las armas de la nación. Independencia y ciudadanía en Hispanoamérica (1750-1850). Manuel Chust y Juan Marchena (eds.) (Madrid, Iberoamericana, 2007), 81-110.

Chust, Manuel y Juan Marchena, Juan, «De milicianos de la Monarquía a guardianes de la nación». Las armas de la nación. Independencia y ciudadanía en Hispanoamérica (1750-1850). Manuel Chust y Juan Marchena (eds.) (Madrid, Iberoamericana, 2007), 7-14.

Chust, Manuel, Ciudadanos en armas. La Milicia Nacional en el País Valenciano (1834-1840) (Valencia: Institución Alfonso el Magnánimo, 1987).

Engels, Friedrich, El origen de la familia, de la propiedad privada y del Estado (Madrid: Akal, 2017). Original de 1884.

Escudero, José Antonio, El rey: historia de la monarquía, vol. 2 (Barcelona: Planeta, 2008).

Espadas Burgos, Manuel, La Milicia Nacional (Madrid: Ayuntamiento de Madrid, 1972).

Gallego, Alfredo, «España 1812: Cádiz, Estado unitario, en perspectiva histórica», Ayer, 1 (1991): 125-166.

Gambra, Rafael, La primera guerra civil de España (1821-1823), (Madrid: Escelicer, 1972).

García León, José María, La Milicia Nacional en Cádiz (Cádiz, Caja de Ahorros, 1983).

Garralda, José Fermín, «La Milicia Nacional Local de Pamplona durante el trienio constitucional. Estudio sociológico y político de sus componentes», Príncipe de Viana, 49, (1988): 319-333.

Gil, Olga, Atribuciones de la «justicia militar» en España: fiel indicador de nuestra historia reciente (Burgos: Universidad de Burgos, 1999).

Gil Novales, Alberto, El Trienio Liberal. (Zaragoza, Prensas de la Universidad de Zaragoza, 2020). Edición de Ramón Arnabat.

Guerrero, Ana C., Pérez Garzón, Juan S. y Rueda, Germán, Historia política: 18081874 (Madrid: Itsmo, 2004). 
Herrero, Guillermo, Liberalismo y Milicia Nacional en Pamplona durante el siglo XIX (Pamplona: UPNA, 2003).

Idoate Iragui, Florencio, «La merindad de Tudela durante la guerra realista», Príncipe de Viana, 104-105, (1966): 277-300.

Laborie, María C., «Navarra ante el constitucionalismo gaditano», Príncipe de Viana, 104-105, (1968): 237-272.

Lafuente, Modesto, Historia general de España, vol. 18 (Barcelona: Montaner y Simón, 1888).

Marx, Carlos y Engels, Friedrich, Manifiesto del Partido Comunista (Ciudad de México, CES, 2011). Original de 1848.

Millán, Jesús, «Poder político y legitimación social antes del «apogeo del Estado»», Alcores, 12, (2011): 257-288.

Moliner Prada, Antonio, «Constitución militar y liberalismo en España (1808-1814)», Revista Universitaria de Historia Militar, 2, (2012): 135-152.

Naranjo, Miguel Ángel, «La Milicia Nacional de Almendralejo», Revista de Estudios Extremeños, 1, (2016): 639-684.

París, Álvaro, «Milicia Nacional». El Trienio Liberal (1820-1823). Una mirada política. Pedro Rújula e Ivana Frasquet (Coords.) (Granada, Colmares, 2020), 213-262.

Pérez Garzón, Juan Sisinio, Milicia nacional y revolución burguesa: el prototipo madrileño, 18o8-1874 (Madrid: CSIC, 1978).

Pro, Juan, «La construcción del Estado en España: haciendo historia cultural de lo político», Almanack, 13, (2016): 1-30.

Rico, José María, Policía y sociedad democrática (Madrid: Alianza, 1983).

Río, Ramón del, Orígenes de la guerra carlista en Navarra. 1820-1824 (Estella: Gobierno de Navarra, 1987).

Roca, Jordi, Política, Liberalisme i Revolució. Barcelona, 1820-1823 (Barcelona, Universidad Autónoma de Barcelona, 2007).

Romero Alpuente, Juan, Historia de la revolución española y otros escritos, vol. 1 (Madrid: CEC, 1989).

Ruiz de Morales, Joaquín, Historia de la Milicia Nacional desde su creación hasta nuestros días (Madrid: Prats y Ruiz, 1855).

Rújula, Pedro y Chust, Manuel, El Trienio Liberal. Revolución e independencia (182O1823) (Madrid: Catarata, 2020).

Rújula, Pedro, Constitución o Muerte. El Trienio Liberal y los levantamientos realistas en Aragón (1820-1823) (Zaragoza: Rolde, 2000).

Sánchez Jiménez, José, La España contemporánea. De 1808 a 1874 (Madrid: Itsmo, 1991).

Sánchez Mantero, Rafael, Fernando VII. Un reinado polémico (Madrid: Historia 16, 1996).

Seco Serrano, Carlos, Militarismo y civilismo en la España contemporánea (Madrid, Instituto de Estudios Económicos, 1984). 
Sorando, Luis y Manzano, Antonio, «La milicia nacional de Zaragoza (1820-1823)», Emblemata, 6, (2000): 177-212.

Veiga, Xosé R., «La Milicia Nacional como espacio de politización liberal en Galicia (1820-1844)». XV Congreso de Historia Agraria de la SEHA, 2016.

Veiga, Xosé R., «Poderes locales y construcción del Estado en el siglo XIX(1808-1874)», Ayer, 108, (2017): 285-302.

VV. AA, Resumen Histórico de las ocurrencias de Zaragoza desde el 23 de agosto hasta el 16 de septiembre del presente año de 1821 (Zaragoza: Imprenta de Miedes, 1821).

Weber, Max, El Político y el Científico (Madrid: Alianza, 1979). Original de 1919. 